\title{
GESTÃO DOS NEGÓCIOS PÚBLICOS E A RESOLUÇÃO EXTRAJUDICIAL DOS CONFLITOS EM FACE DA ADMINISTRAÇÃO PÚBLICA GERENCIAL
}

\author{
MANAGEMENT OF PUBLIC BUSINESS AND THE RESOLUTION \\ EXTRAJUDICIAL OF CONFLICTS IN FACE OF PUBLIC ADMINISTRATION \\ MANAGEMENT
}

\author{
${ }^{1}$ Lara Caxico Martins Miranda \\ ${ }^{2}$ Marlene Kempfer
}

\section{RESUMO}

Com a crise socioeconômica mundial na década de 1980, tem-se discussões sobre o papel do Estado diante das relações público-privadas. Dentre as críticas sobre a realidade de então, no Brasil, destaca-se, os resquícios da gestão pública patrimonialista e os excessos da burocrática. Neste contexto, Bresser Pereira nas obras (1998, 2005, 2009), traz estudos sobre as possibilidades da Administração Pública Gerencial. O foco da pesquisa está em considerar tais fundamentos em face das atuais possibilidades de administração dos conflitos, em negócios públicos, por caminhos extrajudiciais da arbitragem (Lei 9.307/96 e Lei 13.129/15) e da autocomposição (Lei 13.140/15).

Palavras chave: Administração Pública Gerencial; Resolução de Conflitos Público-Privados; Patrimônio Público Disponível.

\begin{abstract}
With the global socio-economic crisis in the 1980s, there has been discussion about the role of the state in the face of public-private relationships. The criticisms of the reality of the time, in Brazil, stands out the remnants of patrimonialist public administration and the excesses of bureaucracy. Bresser Pereira in the works $(1998,2005,2009)$, brings studies on the possibilities of Management Public Administration. This research is to consider such grounds in the face of the current possibilities of management of conflicts, in public affairs, nonjudicial ways of arbitration (Law 9.307/96 and 13.129/15) and selfcomposition (Law $13.140 / 15)$
\end{abstract}

Keywords: Public Administration Management; Resolution Of Public-Private Conflicts; Public Property Available.

\footnotetext{
${ }^{1}$ Mestranda do Programa de Mestrado em Direito Negocial da Universidade Estadual de Londrina - UEL, (Brasil). E-mail: mkempferb@gmail.com

${ }^{2}$ Doutora em Direito do Estado pela Universidade Católica de São Paulo - PUC/SP, (Brasil). Professora do Mestrado em Direito Negocial e da Graduação da Universidade Estadual de Londrina/PR.

E-mail: laracaxico@ hotmail.com
} 


\section{INTRODUÇÃO}

Os insucessos das reformas administrativas públicas ocorridas no Brasil nas décadas de 1930 e 1960 apontaram para a necessidade de regimes jurídicos que possibilitassem atuação do Estado de modo mais eficiente. Para tanto, identificou-se a necessidade de importar experiências da gestão empresarial privada para o âmbito público, preservando, contudo, os interesses públicos. Desde então o legislador passou a positivar vários caminhos para promover uma gestão pública mais efetiva.

A Administração Pública Gerencial foi inaugurada, no ordenamento jurídico, com a emenda constitucional 19/98, que introduziu no artigo 37 o valor da eficiência. No entanto, mesmo antes desta inovação, já eram ensaiados passos que culminaram com um regime jurídico administrativo que permitiu uma atuação diferenciada do gestor público. Dentre as possibilidades de atuação destaca-se expansão de competências discricionárias e, consequentemente, maior liberdade no exercício da função administrativa e regulamentar; ampliação o controle social dos governos; possibilidade de promover controles internos posteriores à prática de atos ou contratos administrativos.

O regime jurídico administrativo gerencial que vem sendo construído acrescenta o dever de justificar as escolhas públicas por meio de valores de grande envergadura, como economicidade, proporcionalidade, razoabilidade e equidade, sem excluir os controles tradicionais dos atos administrativos. Acima de tudo, este pretende garantir a qualidade no cumprimento dos deveres dos gestores públicos.

A aproximação do regime gerencial privado, que rege interesses particulares (empresarial ou não), do arcabouço jurídico-administrativo permite, por exemplo, prevenir e solucionar conflitos, em que é parte pessoa jurídica de direito público, percorrendo caminhos extrajudiciais. No Brasil, há caminhos extrajudiciais de solução de conflitos para o âmbito público que estão positivados. São eles: heterocomposição, exemplificada pela arbitragem (Leis 9.307/96 e Lei 12.129/15) e autocomposição, que se realiza através da mediação realizada pela Advocacia Pública (Lei 13.140 de junho de 2015). Estes, e outros instrumentos normativos, evidenciam a importação de soluções já aplicadas nas relações privadas.

Apesar desta utilização, é preciso promover estudos para indicar os fundamentos da competência de mediadores e árbitros que atuem na resolução de conflitos que envolvam o 
ente público e os limites a serem considerados, pela razão fundamental de que estão em análise interesses ou patrimônios públicos. A pesquisa desenvolvida será dedutiva exploratória e utilizará como técnica a pesquisa bibliográfica. Percorrerá os aspectos da administração pública gerencial a partir dos estudos do professor Luiz Carlos Bresser Pereira, analisará o regime jurídico administrativo em face do valor da eficiência constitucionalizado por meio da emenda constitucional 19/98, e discutirá a utilização e os limites da arbitragem e mediação para resolução de conflitos em que uma das partes seja pessoa jurídica de direito público na função administrativa.

\section{Reforma do Estado Brasileiro à luz dos argumentos de Premissas do Prof. Luiz Carlos Bresser Pereira}

A reforma administrativa, iniciada no Brasil em 1960, foi objeto de estudo de Luiz Carlos Bresser Pereira nas obras publicadas em 1998, 2005 e 2009. Intituladas respectivamente de Reforma do Estado para a Cidadania, Reforma do Estado e Administração Pública Gerencial e Construindo o Estado Republicano: democracia e reforma da gestão pública, todas trataram acerca das transformações vivenciadas com as reformas patrimonial, burocrática e a gerencial, as superações de alguns sistemas e a manutenção de outros. No Brasil, a positivação dos ideias gerenciais se iniciou com a publicação do Decreto-lei n. 200/67, que trouxe traços do que seria uma administração pública descentralizada.

Luiz Carlos Bresser Pereira explica que, com a publicação do decreto mencionado pelo governo militar, a administração pública objetivava superar a rigidez burocrática por meio da atuação das fundações, autarquias, empresas públicas e sociedades de economia mista. Por essa razão, foi considerado como um primeiro momento legislativo da administração gerencial no Brasil. (BRESSER PEREIRA, 2005, p.244). O legislativo pretendia abrir espaço para a promoção da eficiência e ampliação da autonomia administrativa através do fortalecimento da administração indireta e descentralizada. Este posicionamento se coadunava com o princípio da flexibilização, promovido pela administração gerencial. Neste momento, solidificou-se a distinção entre a administração direta e indireta e as possibilidades de suas atuações (BRESSER PEREIRA, 1998, p.167).

Apesar dos benefícios vividos pela descentralização e consequente desburocratização, o poder constituinte de 1988 desconsiderou os direcionamentos gerenciais para a administração pública a ser positivada na Carta Magna. Ao invés, optou por prosseguir 
com a gestão burocrática que já estava em andamento. Apenas posteriormente, com a publicação da Emenda Constitucional n. 19 de 1998 houve atenção legislativa para os princípios da administração pública gerencial (BRESSER PEREIRA, 2005, p.246). Vale mencionar que o retrocesso administrativo percebido na Constituição de 1988 não decorreu da inefetividade da proposta trazida pelo Decreto-Lei mencionado, mas sim do esforço político, realizado durante a transição para a democracia, para a desestatização. Isso fez com que o constituinte de 1988 ampliasse o controle burocrático frente às instituições da administração indireta que tinham se tornado mais autônomas graças ao decreto de 1967 (BRESSER PEREIRA, 1998, p. 177).

Apenas com o governo de Fernando Henrique Cardoso, em 1995, foi identificada uma atuação governamental em prol da flexibilização e desburocratização. Neste momento, com a reforma da administração pública, o Estado passou a se reestruturar e se inserir no mundo globalizado. Esta não significou a desorganização, quebra do Estado, alteração do seu sistema político de decisões, nem mesmo diminuição da sua atuação regulatória. A proposta significava mudar a atuação do Estado em vistas de se implementar visões contemporâneas de mercado e atender as novas necessidades sociais (BRESSER PEREIRA, 2005, p.15).

Para tanto, foi idealizado por Luiz Carlos Bresser Pereira, ministro da reforma, o Ministério da Administração Federal e Reforma do Estado, cuja prioridade era reorganizar a administração pública nas áreas fiscais e de previdência social. Além disso, o órgão objetivava eliminar os monopólios estatais, para que a atuação pública se tornasse mais eficiente e competitiva. Para a inserção do Brasil na economia capitalista atual era fundamental a flexibilização da atuação dos servidores públicos e a aproximação dos mercados público e privado (BRESSER PEREIRA, 2005, p.21-22).

A reforma administrativa e a construção de uma gestão gerencial não foi bem recebida pelos gestores da época. Apesar disso, em pouco tempo foi possível notar a sua necessidade, o que fez com que grupos políticos e empresariais passassem a apoiá-la e incentivá-la. Tanto no âmbito interno quanto no âmbito externo investidores estrangeiros e agências financiadoras passaram a exigir a transformação da administração pública brasileira (BRESSER PEREIRA, 2005, p.22).

A reforma foi importante em virtude da crise estatal vivenciada no período e da necessidade de solucionar os problemas de crescimento populacional, diferenciação de estruturas e aumento das complexidades negociais (BRESSER PEREIRA, 2005, p.242). Pode-se afirmar que esta teve como objetivos reduzir custos de atividades realizadas pelo 
governo e tornar mais efetivas as prestações de serviços públicos diante dos administrados, protegendo dessa forma o patrimônio e bens públicos.

Esta foi ainda direcionada para o melhor atendimento dos cidadãos e para o alcance de resultados na atuação administrativa. Uma das suas premissas era não conferir grau elevado de confiança aos funcionários públicos, em virtude do nepotismo que assolou o período de vigência da administração patrimonial. Além disso, descentralizar as atividades, diferentemente da concentração vivida no auge da administração burocrática. A reforma buscou ainda o incentivo à inovação e criatividade na prática administrativa, passando a fazer o controle sobre os agentes públicos pelo contrato de gestão (BRESSER PEREIRA, 2005, p.28).

Com relação aos controles de atos e contratos públicos, a administração burocrática se fundamentava no excesso de procedimentos prévios. A administração gerencial, por sua vez, tinha o foco nos resultados da atuação governamental e por essa razão apregoava a predominância dos controles posteriores. Nesse viés, implementou-se programas de delegação de competências para a administração indireta por meio da descentralização e para órgãos da administração direta através da desconcentração. Acreditava-se que quanto maior a quantidade de órgãos atuando de maneira especializada na consecução do interesse público mais possível seria o alcance de resultados satisfatórios. Com a administração pública gerencial, o controle de desempenho passou a ser aferido por indicadores previamente definidos nos negócios jurídicos públicos (BRESSER PEREIRA, 2005, p. 23-29).

Vê-se que o novo modelo de administração criou novos institutos e também alterou a estratégia de gestão da máquina pública. (BRESSER PEREIRA, 2005, p.33). Os controles, que antes eram realizados a priori, passaram a ser posteriores à realização do negócio jurídico, sendo caracterizados em virtude da:

a) descentralização do ponto de vista político, transferindo recursos e atribuições para os níveis políticos regionais e locais; b) descentralização administrativa, através da delegação de autoridade para os administradores públicos transformados em gerentes crescentemente autônomos; c) organizações com poucos níveis hierárquicos ao invés de piramidal, d) pressuposto da confiança limitada e não da desconfiança total; e) controle por resultados, a posteriori, ao invés do controle rígido, passo a passo, dos processos administrativos; e f) administração voltada para o atendimento do cidadão, ao invés de auto-referida (BRESSER PEREIRA, 2005, p.243).

A reforma administrativa gerencial não se preocupou apenas em trazer uma atuação empresarial privada para o Estado. Concomitantemente à exigência de eficiência nos órgãos 
públicos, identificou também a necessidade de trabalhar as abordagens sociais, democráticas e liberais. No âmbito social democrático a reforma incentivou a atuação popular através de controles sociais, publicou medidas de exigência à transparência pública e instituiu o Estado como assegurador de direitos sociais independentemente de crises financeiras. No âmbito social liberal, firmou parcerias entre o Estado e o mercado, por acreditar ser este patrocinador de recursos e impulsionador da economia (BRESSER PEREIRA, 2009, p.253).

É certo que o advento da administração pública gerencial não fez com que os resquícios burocráticos fossem abandonados. A operação eficiente compreende um processo diário a ser realizado pelos agentes e órgãos estatais em busca da segurança e inovação tecnológica, utilizados em grande escala no âmbito privado.

\section{Regime Jurídico Administrativo em face da Administração Pública Gerencial}

O regime jurídico Administrativo, nos termos apresentados pelo professor Celso Antônio Bandeira de Mello (2011, p. 95), tem por pilares os princípios da supremacia do interesse público sobre o particular e o da indisponibilidade do interesse público pela Administração. Estas regras estruturais têm em comum proteger o interesse público. Embora conceituar o que seja interesse público dependa do momento e do espaço, destaque-se a interpretação de que é a "dimensão pública dos interesses individuais", ou seja, "deve ser conceituado como o interesse resultante do conjunto dos interesses que os indivíduos pessoalmente têm quando considerados em sua qualidade de membros da sociedade e pelo simples fato de o serem" (BANDEIRA DE MELLO, 2011, p. 53-57).

A supremacia do interesse público sobre o privado possibilita ao Estado agir em posição de comando frente aos particulares e possuir posição privilegiada nas relações com os particulares. Com relação à primeira conduta, permite-se constituir os privados em obrigações por meio de ato unilateral e até mesmo modificar, da mesma forma, relações já estabelecidas. O segundo agir indica a presunção de veracidade e legitimidade dos atos administrativos, benefício de prazos estendidos no processo judicial, transferência para o particular do ônus de prova e prazos especiais para prescrições de ações (BANDEIRA DE MELLO, 2011, p. 6070).

A indisponibilidade do interesse público é regra que proíbe ao gestor dispor sobre os interesses qualificados como públicos pela sociedade, pois alcançaram o patamar de inapropriáveis. Os bens e interesses sociais não estão à mercê da vontade do administrador, 
mas sim cabe a este protegê-los. Decorre desta regra o dever da observância do regime legal e suas sucessivas implicações, tais quais: princípio da finalidade, da razoabilidade, da proporcionalidade, da motivação, da obrigatoriedade do desempenho da atividade pública, o controle administrativo, a isonomia entre os administrados, a publicidade e o controle jurisdicional dos atos administrativos (BANDEIRA DE MELLO, 2011, p. 65-74).

Com o advento da Emenda Constitucional 19/98, marco da administração pública gerencial, o regime jurídico administrativo apresentado continuou sendo o norteador da função administrativa. No entanto, em alguns setores foi preciso ser relido de maneira mais expressiva. Observa-se que cresceu o número das competências discricionárias atribuídas pela lei ao administrador público; enfatizou-se os controles posteriores das ações no desempenho da função administrativa; ampliou-se a autonomia administrativa e financeira (agências reguladoras); foram criadas mais oportunidades para diálogo social direto (audiências e consultas públicas), construindo soluções que além de legítimas estarão legitimadas; e desenvolveu-se a prevenção e solução de conflitos por meio do diálogo ou acordo fora do Judiciário. Especialmente diante desta atuação, a tradicional rigidez da posição de verticalidade da administração pública foi, em grande aspecto, revisitada e por essa razão caminha para uma administração pública construída pelo consenso.

O novo grau de competência discricionária muito se relaciona com o emprego de termos abertos ou indeterminados nos textos do direito positivo. Embora possibilite mais liberdade para administrar e, portanto, maior agilidade e eficiência na gestão, traz maior responsabilidade jurídica ao gestor que deverá motivar, exaustivamente, suas decisões. Este é o caminho para que o controle posterior seja eficiente.

A Lei 11.079/04, que instituiu normas gerais para licitação e contratação de parceria público-privada no âmbito da administração pública, e a Lei 12.462/11 que disciplina regime diferenciado de contratações, são exemplos destas novas possibilidades para a gestão dos interesses públicos. Cita-se os artigos para análise:

Lei $11.079 / 04$

(...)

Art. 10. A contratação de parceria público-privada será precedida de licitação na modalidade de concorrência, estando a abertura do processo licitatório condicionada a:

(...)

VI - submissão da minuta de edital e de contrato à consulta pública, mediante publicação na imprensa oficial, em jornais de grande circulação e por meio eletrônico, que deverá informar a justificativa para a contratação, a identificação do objeto, o prazo de duração do contrato, seu valor estimado, 
fixando-se prazo mínimo de 30 (trinta) dias para recebimento de sugestões, cujo termo dar-se-á pelo menos 7 (sete) dias antes da data prevista para a publicação do edital; e (grifo nosso)

(...)

Lei $12.462 / 11$

Art. $1^{\circ}$ É instituído o Regime Diferenciado de Contratações Públicas (RDC), aplicável exclusivamente às licitações e contratos necessários à realização:

(...)

$\S 1^{\circ}$ O RDC tem por objetivos:

I - ampliar a eficiência nas contratações públicas e a competitividade entre os licitantes

(....)

Art. $7^{\circ}$ No caso de licitação para aquisição de bens, a administração pública poderá:

I - indicar marca ou modelo, desde que formalmente justificado, nas seguintes hipóteses:

(...)

Art. 11. A administração pública poderá, mediante justificativa expressa, contratar mais de uma empresa ou instituição para executar o mesmo serviço, desde que não implique perda de economia de escala, quando:

O estudo exposto e os exemplos apresentados, para fins didáticos, permitem argumentar que as diretrizes da administração pública gerencial já se fazem presente no atual ordenamento jurídico. Entre tais constatações, destaque-se a autorização legal para a solução extrajudicial de conflitos e gestão os negócios públicos por meio da arbitragem (Lei n. 9.307/96) ou autocomposição (Lei 13.140/15).

Está no domínio das competências públicas administrar os interesses que foram qualificados como públicos. No âmbito administrativo, tais atribuições se concretizam por meio de contratos públicos e privados em que a administração está em nível horizontal na relação jurídica. Neste contexto, a pesquisa abordará os contratos na esfera pública que se incluem como espécies do gênero negócios jurídicos públicos.

O regime jurídico geral dos negócios jurídicos está na esfera privada. Ao aproximar tal arcabouço jurídico para os negócios jurídicos públicos, certamente, uma das diferenças está na manifestação autônoma da vontade do agente público. Edmir Araújo (1992, p. 25) esclarece que o agente público, agindo como Fazenda Pública, fundação ou órgão público, sempre atua em obediência à vontade do Estado, que é em suma a vontade legal. Não há autonomia privada do agente, pois este deve respeitar o princípio da legalidade. Por essa razão concluiu-se que diante dos negócios jurídicos tratados no estudo, não há prevalência da vontade do negociante público. A conceituação de negócios jurídicos administrativos perpassa a ideia mencionada de manifestação de vontade. Este é tratado como sendo 
(...) o acordo de vontades do qual participa a Administração, a qual, não abdicando da potestade pública de que é detentora, celebra com o particular determinados pactos, objetivando o interesse público; ou o acordo de vontades entre entidades da própria Administração, em qualquer de suas esferas, objetivando a consecução de fins comuns a essas entidades, de personalidade jurídicas próprias (ARAÚJO, 1992, p. 212).

Vale destacar que os negócios jurídicos administrativos não se confundem com os atos administrativos. Segundo Celso Antônio Bandeira de Mello os atos administrativos são

declaração do Estado (ou de quem lhe faça as vezes - como por exemplo, um concessionário de serviço público), no exercício de prerrogativas públicas, manifestada mediante providências jurídicas complementares da lei a título de lhe dar cumprimento, e sujeitas a controle de legitimidade por órgão jurisdicional (BANDEIRA DE MELLO, 2011, p. 352).

Ainda que os atos administrativos tenham como elemento de existência a manifestação de vontade do Estado, não se confundem com os negócios jurídicos públicos. Isso porque, segundo Edmir Araújo (1992, p. 168), no caso de atos administrativos, o Poder Público manifesta sua vontade de maneira unilateral. $\mathrm{O}$ ato administrativo adentra ao mundo jurídico produzindo efeitos no mesmo momento em que é emanado pelo Estado, independentemente de aceitação da parte que será afetado por ele. Mesmo quando várias vontades unilaterais são manifestadas pelo Estado não é possível a formação de um negócio jurídico. Reforça Maria Sylvia Zanella Di Pietro (2016, p.267) que em tais situações estar-seá diante de atos administrativos complexos, cujas vontades formam um ato único.

É preciso chamar a atenção para a diferença entre contratos administrativos e aqueles denominados pela doutrina de contratos da administração. Para estes as relações jurídicas entre os participantes estão em nível horizontal e regidos por normas contratuais construídas sob o manto das relações privadas, embora subrrogadas por normas de ordem pública. Nestas situações não se aplica, na integralidade, o regime jurídico administrativo. Tem-se, como exemplo, a compra e venda de um imóvel ou a locação de uma casa para a atuação de uma autarquia (BANDEIRA DE MELLO, 2011, p. 568). Tais contratos serão regidos pela lei de locações, mas, a ele deve preceder um processo licitatório, para garantir o valor da isonomia e estará sob controle interno e externo próprios da administração pública.

Nos contratos administrativos há aplicação do regime jurídico público. Da análise das normas que os regulam tem-se a posição de verticalidade do órgão público e as prerrogativas unilaterais (cláusulas exorbitantes), que possibilitam a persecução dos interesses públicos. A possibilidade de alteração unilateral do contrato só pode afetar, segundo Hely 
Lopes Meirelles (2011, p.220), as cláusulas regulamentares, que são “aquelas que dispõem sobre o objeto do contrato, mas sem modificar o núcleo do objeto originalmente pactuado, sob pena de nulidade, e o modo de sua execução". As cláusulas de equilíbrio econômico devem ser mantidas e são direito da parte privada.

Dentre as espécies de contratos administrativos que inauguram as novas possibilidades de manifestação da administração pública gerencial, exemplificativamente, destaca-se os contratos de concessão de serviços públicos (Lei n. 8.987/95 e 9.074/95). Ainda mais recentes, tem-se os contratos de concessão de parcerias público-privadas (Lei n. 11.079/04) e aqueles sob o Regime Diferenciado de Contratação (Lei n. 12.462/11). Neste último caso, salienta-se a sua aplicação para a contratação em setores estratégicos, tais quais as do Programa de Aceleração do Crescimento e obras e serviços de engenharia no âmbito do Sistema Único de Saúde.

O regime jurídico destes contratos, a partir das regras que os regem, expõe os objetivos gerenciais que sempre estiveram presentes na gestão de negócios privados, tais quais: delegar, fiscalizar, controlar a qualidade e competir. Nos textos legais mencionados há a possibilidade de delegar a prestação de serviços públicos à pessoas jurídicas ou consórcio de empresas; realizar a fiscalização na prestação do serviço para garantir a sua qualidade; elevar o controle de qualidade para a competitividade global da economia nacional; autorizar pagamento conforme o desempenho do parceiro privado, metas cumpridas e padrões de qualidade; e usar os meios da arbitragem e mediação para solução de conflitos na esfera extrajudicial.

Luiz Carlos Bresser Pereira (1998, p. 232) aponta ainda outras flexibilizações trazidas aos negócios jurídicos com implementação da administração pública gerencial nos negócios jurídicos públicos:

A dispensa, para as agências executivas, da obrigatoriedade da firmatura de
termos aditivos a convênios de vigência plurianual - quando destinados
exclusivamente à indicação do crédito orçamentário que dará suporte ao
gasto no exercício - é, também, medida de racionalização administrativa e as
poupará de atividades burocráticas, substituídas pela publicidade dada às
notas de movimentação de crédito ou de empenho emitidas.

Carlos Alberto de Salles expõe que a utilização de meios extrajudiciais de solução de conflitos deve ser compreendida no contex to do processo de reforma do Estado, em virtude da privatização de empresas e serviços públicos e pela utilização estratégica de governo indireto. 
A arbitragem, por exemplo, se torna parte da estratégia de gestão dos negócios do Estado (SALLES, 2011, p. 61).

A partir da análise exposta concluiu-se que o regime jurídico que identifica a Administração Pública Gerencial, no aspecto dos negócios públicos, trouxe maior autonomia aos agentes públicos para a gestão. Reforça-se o argumento de que maior grau de autonomia não significa autonomia plena. $\mathrm{O}$ gestor público estará sempre submetido ao regime legal. A maior liberdade que passou a ter, para ser amparada no atual ordenamento jurídico, deverá vir acompanhada de motivação para justificar as escolhas que fez ao realizar negócios públicos.

\section{Caminhos Extrajudiciais para Solução de Conflitos em Negócios Jurídicos}

\section{Públicos}

Os meios extrajudiciais de solução de controvérsias são buscados pelas partes no âmbito privado, em regra, em razão da celeridade, especialização do terceiro envolvido e maior participação direta das partes. Estes mesmos argumentos são compatíveis com o regime jurídico administrativo gerencial. Portanto, é possível recorrer às vias da heterocomposição, como a arbitragem (Lei n. 9.307/96 e Lei n. 13.129/15) e da autocomposição administrativa, que resultam de transações com a mediação realizada pela Advocacia Pública (Lei n. $13.140 / 15)$.

Diante de negócios públicos sempre haverá o interesse público a ser tutelado, portanto, será preciso delimitar a atuação do gestor público, em nível legal e regulamentar. Entre tais limites, a utilização dos meios extrajudiciais referidos exige que o patrimônio envolvido nas negociações tenha a qualificação de patrimônio público disponível, mesmo que tal exigência não seja explicitamente indicada. $\mathrm{O}$ fundamento está no princípio da legalidade, que indica que em se tratando de bens públicos a disponibilidade dependerá, sempre, de previsão legal.

\subsection{Limite do patrimônio disponível na utilização dos meios extrajudiciais de solução de conflitos}

A Lei n. 9.307/96 dispõe em seu artigo $1^{\circ}, \S 1^{\circ}$, que "a administração pública direta e indireta poderá utilizar-se da arbitragem para dirimir conflitos relativos a direitos patrimoniais disponíveis". Isso significa que o contrato cujo objeto recai a arbitragem deverá ter o caráter 
de patrimonialidade e disponibilidade. A Lei n. 13.140/15, que trata da autocomposição (mediação) de conflitos no âmbito da administração pública, faz menção expressa sobre esta exigência em seu artigo $3^{\circ}$ quando explicita que "pode ser objeto de mediação o conflito que verse sobre direitos disponíveis ou sobre direitos indisponíveis que admitam transação". Assim, defende-se que a exigência de disponibilidade do objeto em conflito é limite primeiro a ser analisado diante da discricionariedade do gestor público.

Segundo Eugênia Cristina Cleto Marolla (2016, p. 88-89), "são patrimoniais os direitos passíveis de valoração pecuniária, ou seja, aqueles que podem ser avaliados em dinheiro e que, por conseguinte, possuem interesse econômico". Quanto a tais direitos serem disponíveis aponta duas correntes que tratam da relação entre a disponibilidade do direito e o interesse público.

Celso Antônio Bandeira de Mello (BANDEIRA DE MELLO, 2014, p. 734) e Lúcia Valle Figueiredo (FIGUEIREDO, 2006, p. 115-116) defendem, na primeira corrente, que os mecanismos de resolução extrajudicial de conflitos não são compatíveis com o interesse público. Para os autores, não há que se falar em disponibilidade de direitos patrimoniais quando se trata de contratos administrativos. Celso Antônio Bandeira de Mello, inclusive, expõe ser "lamentável" a positivação da arbitragem como meio de resolução de lides envolvendo o poder público, presente na lei de concessões e de parcerias público privadas (BANDEIRA DE MELLO, 2014, p. 77).

A segunda corrente, direcionada por Eros Roberto Grau (2000, p. 17-19), entende que a indisponibilidade é regra, em virtude da impossibilidade de negociar interesses públicos fora dos limites da constituição. Apesar disso, seria cabível, a título de exceção, a indisponibilidade relativa, quando se estiver diante de interesses secundários da administração. Os interesses secundários são caracterizados como aqueles dispostos à alcançar os interesses primários e por essa razão teria o caráter patrimonial e disponível (MAROLLA, 2016, p. 110). Também no sentido de que a indisponibilidade do interesse público não se refere, em todas às ocasiões, que os direitos protegidos pela Administração sejam indisponíveis, o autor afirma que não há relação indissociável entre a disponibilidade do interesse público ou sua indisponibilidade com direitos patrimoniais (GRAU, 2000, p. 1719).

Apesar da pouca abordagem doutrinária a respeito do conceito de patrimônio disponível, a doutrina indica que alguns critérios, além da análise do interesse primário e secundário, que podem ser utilizados para alcançar este conhecimento. Joaquim de Paiva 
Muniz (2004, p.93) entende que para tanto se faz necessário verificar se a atuação administrativa se deu com atos de gestão ou atos de império.

Explica o autor que atos de império (ius imperium) são aqueles em que a Administração pratica com superioridade e soberania diante dos demais. Em geral são utilizados para garantir a prevalência do interesse público. Os atos de gestão (ius gestioni), por outro lado, são os praticados em posição de verticalidade com o particular, pois não objetivam fins públicos, mas sim atender a interesses particulares do Estado (MUNIZ, 2004, p.93).

Há ainda o critério que identifica do patrimônio indisponível considerando as normas de ordem pública. Segundo Manoel Pereira Barrocas (2014, p. 310), estas seriam as opções sociais, positivadas pelo legislador, como de obrigação imperativa. Não há margem de atuação para o destinatário da norma de ordem pública, o que indica uma imposição do Estado. A análise desse critério conclui que questões que envolvam normas de ordem pública não estariam sujeitas à arbitragem e, por essa razão, não poderiam ser consideradas como patrimônio disponível.

Apesar dos critérios apontados, Eugênia Cristina Cleto Marolla (2016, p. 115-130) anota que nenhum deles é capaz de individualmente conceituar patrimônio disponível. Afirma ela que, para alcançar, diante do caso concreto, o conceito mencionado, inicialmente é preciso verificar o modo como ocorreu a atuação estatal. Deve-se verificar se a Administração atuou em posição de verticalidade ou horizontalidade diante do particular, ou seja, com atos de império ou atos de gestão. Posteriormente é fundamental verificar se o objeto central da análise pode ser alienado, renunciado e transacionado pelo poder público. Este critério pode ser verificado a partir de uma minuciosa análise legal, pois, em virtude do princípio da legalidade, só esta pode determinar tais circunstâncias. A partir dessas análises é possível verificar se a administração está tratando de direitos com caráter patrimonial e disponível.

Conclui que:

Não existe um critério geral que permita determinar os direitos disponíveis da Administração. A verificação da disponibilidade deverá ser feita ante o caso concreto, posto tratar-se de um conceito jurídico indeterminado, possuindo, como consequência, máxima generalidade e mínimo conteúdo normativo. (MAROLLA, 2016, p.115)

Identificar patrimônio disponível, portanto, é conceito com termos indeterminados e que caberá à lei ou ao regulamento traçar diretrizes para identifica-lo. Quando a lei autorizar 
que esta qualidade seja atribuída por ato administrativo, o controle de legalidade e de constitucionalidade destas normas terá como referência o regime jurídico administrativo constitucional.

\subsection{Caminho da Heterocomposição (Arbitragem) para Solução de Conflitos Públicos}

A análise realizada leva a conclusão de que a busca pela flexibilização levou o legislador a positivar, como mecanismo da desburocratização, meios extrajudiciais de resolução de conflitos. Dentre eles, está a arbitragem, prevista inicialmente de maneira individual em leis específicas que regem contratos administrativos. Exemplo é encontrado na Lei n. 11.079/04, que trata acerca das parcerias público privadas. No artigo 11, inciso III deste instituto legal, há a previsão da possibilidade de que o edital da licitação indique que os conflitos derivados dos contratos firmados poderão ser solucionados por meios privados de resolução de disputas.

Luís Roberto Barroso (2012, p. 1274 apud MAROLLA, 2016, p. 69) e Carlos Alberto Salles (2011, p. 215), mesmo antes da promulgação da Lei n. 13.129/15 entendiam que havia necessidade de que lei expressa autorizasse o uso da arbitragem pela Administração Pública. Isso porque, para eles, o uso deste meio extrajudicial de resolução de conflito acabava por afastar a análise da lide por parte do judiciário. Mesmo o argumento de que a celeridade sustentaria o uso da arbitragem ainda que sem expressa designação legislativa não afastava a concepção destes de que o princípio da legalidade deveria ser respeitado.

Com a publicação da Lei n. 13.129/15, que incluiu na Lei n. 9.307/96 o $§ 1^{\circ}$ do artigo $1^{\circ}$, a discussão acerca da autorização do uso da arbitragem para a administração pública se findou. Isso porque, através daquela foi positivado que "a administração pública direta e indireta poderá utilizar-se da arbitragem para dirimir conflitos relativos a direitos patrimoniais disponíveis". Apesar disso, por possuir o contrato administrativo regime jurídico diverso dos contratos particulares, a arbitragem no âmbito público não possui todas as características daquela realizada no âmbito privado.

Inicialmente destaca-se que a arbitragem no âmbito privado se fundamenta pela autonomia de vontade das partes (SALLES, 2011, p. 33-34). Estas se vinculam através da convenção de arbitragem e caso uma dessas não cumpra o acordado, há a possibilidade de exigir judicialmente a instituição da arbitragem por meio de tutela específica, conforme prevê o artigo $7^{\circ}$ da Lei 9.307/96. A vontade das partes ainda se manifesta na possibilidade de livre 
escolha das regras de direito que serão aplicadas na arbitragem, conforme artigo $2^{\circ}$ do mesmo instituto legal.

Não obstante, mesmo em se tratando de uma das principais características da arbitragem, não é a autonomia da vontade que rege os contratos administrativos. Ao contrário, é o interesse público e a legalidade que movimenta a Administração Pública (SALLES, 2011, p. 37). Os contratos administrativos são regulados por um procedimento formal em que o particular manifesta apenas sua vontade de participar. Por essa razão entende-se que o compromisso arbitral não vincula à administração, que poderá desistir, motivadamente, da arbitragem, em virtude do interesse público. Ademais, o procedimento arbitral será previamente definido pela administração, em conformidade com o regime jurídico de direito público, não podendo adotar as regras do regime privado.

Outra característica inerente à arbitragem é a confidencialidade, apesar de esta não estar expressamente disposta na Lei n. 9.307/96. No âmbito administrativo, não é possível se considerar a confidencialidade como um valor absoluto da arbitragem, tendo em vista o princípio da publicidade dos atos administrativos estampado no caput do artigo 37 da Constituição Federal. Este possui grande importância no âmbito público, pois objetiva garantir a transparência aos administrados.

$\mathrm{O}$ artigo $2^{\circ}, \S 2^{\circ}$ da Lei mencionada dispõe que as partes poderão convencionar que a arbitragem se realize com base nos usos e costumes e nas regras internacionais de comércio. $\mathrm{O}$ artigo 26, inciso IV, por sua vez dispõe que as partes poderão pactuar o local em que será proferida a sentença. Em se tratando de arbitragem a ser realizada pelo poder público, necessário se faz a imposição de limites a estes dispositivos. Na arbitragem construída conforme as regras internacionais, deve ser respeitado o pactuado, mas, no plano interno, deve-se seguir os critérios de competência jurisdicional definidos em nível constitucional e legal para tratar de interesses públicos.

Quanto à possibilidade de arbitragem em negócios públicos internacionais, a respectiva sentença, envolvendo a administração pública, deve ser proferida em língua portuguesa em respeito à regra da transparência e das possibilidades dos controles públicos e sociais. Neste sentido, destaca-se o artigo 23-A da Lei n. 8.987/95, que dispõe sobre o regime de concessão e permissão da prestação de serviços públicos, e o artigo 11 da Lei n. 11.079/04, que dispõe sobre normas gerais para licitação e contratação de parceria público-privada.

A definitividade da sentença arbitral, que indica que o árbitro decide de maneira final a lide, está prevista no artigo 29 da Lei n. 9.307/96. Não há possibilidade de promover 
recursos contra a decisão (artigo 18, Lei n. 9.307/96), mas apenas pedido de correção de erro material e esclarecimento de obscuridade, contradição ou omissão, conforme artigo 30 da lei brasileira de arbitragem. Relativamente ao uso da arbitragem por agentes públicos, entende-se que, em regra, a definitividade da sentença arbitral deve ser mantida, sob pena de se excluir uma grande vantagem dessa opção extrajudicial. Entretanto, em casos em que ocorra violação da lei ou desrespeito ao interesse público, em virtude do regime jurídico administrativo, em especial por que sempre deve ser possível o controle por meio de autotutela (interno) e os externos (Judiciário e Legislativo), entende-se pela possibilidade de revisão e até mesmo anulação da sentença.

A opção pela solução de litígios envolvendo a Administração Pública por meios extrajudiciais de conflitos não deve implicar em renúncia aos princípios constitucionais ou do interesse público, mas sim em um mecanismo para suas efetivações.

\subsection{Caminho da Autocompoisção (Mediação) para a Solução de Conflitos Públicos}

A autocomposição é um caminho, tradicional no âmbito privado, que busca solução e prevenção de conflitos. Apesar disso, possui pouca utilização nas relações público-privadas. A cultura denominada de solução por conciliação diminui a judicialização e traz às partes a convivência com uma justiça construída pelo consenso e não pela imposição, tal qual se verifica na tutela jurisdicional estatal.

Segundo Petronio Calmon,

À inclusão de um terceiro imparcial na negociação dá-se o nome de mediação, que é, pois, um mecanismo para a obtenção da autocomposição caracterizado pela participação de um terceiro imparcial que auxilia, facilita e incentiva os envolvidos à realização de um acordo (CALMON, 2015, p. 111).

Embora os caminhos judiciais sejam válidos e amplamente utilizados, a solução de conflitos por meio de árbitros, mediadores e conciliadores têm maior possibilidade de pacificação social. Além de aproximar as partes por meio do diálogo e da confiança, alcança o objetivo da celeridade e não exclui a possibilidade de recorrer ao Judiciário quando não for cumprido o acordo firmado nos termos disciplinados por lei, uma vez que é um título executivo extrajudicial. 
No Brasil, a Lei n. 13.140/15 possibilita estes caminhos para solução de conflitos, desde que os direitos em desacordo sejam disponíveis e consequentemente admitam serem transigidos. O regime jurídico para esta espécie privada de resolução de conflito, trazido por meio da Lei referida, é composto das seguintes principais normas de estrutura: imparcialidade do terceiro que for o mediador do conflito; isonomia entre as partes envolvidas; oralidade e informalidade no decorrer do uso das técnicas; autonomia de vontade das partes; busca de pacificação pelo consenso; dever de confidencialidade do mediador (exceto com autorização expressa) e das partes quanto às informações veiculadas no processo (exceto, se se tratar de informação que envolva ação pública, conforme artigo 30, § $3^{\circ}$ ); e, finalmente, a boa-fé.

A partir destas propedêuticas considerações pode-se avançar para analisar as normas que a lei traz sobre mediação para permitir a autocomposição administrativa em conflitos em que for parte a pessoa jurídica de direito público, nos termos dos artigos 32 ao 40. As normas contidas nos citados artigos estão no contexto da mediação privada, mas precisam ser interpretadas à luz de regras que compõem o regime da administração pública em seu contexto de administração gerencial. Sendo assim, e partindo dos argumentos acima apresentados sobre o regime jurídico para mediação entre relações privadas, é preciso fazer as considerações a seguir.

As normas que disciplinam a possibilidade de autocomposição são do modal de conduta permitida, portanto, cabe à autoridade administrativa decidir, motivadamente, sobre situações que entende sejam possíveis de soluções por este caminho. No entanto, deve considerar que esta discricionariedade está limitada aos bens e direitos públicos patrimoniais e disponíveis. As partes envolvidas serão pessoa jurídica de direito público e, no outro polo, órgãos da administração pública ou pessoas particulares, sem restrição de ser pessoa física ou jurídica.

Sob aspecto da natureza político-administrativa da federação brasileira, as normas que disciplinam a autocomposição são normas nacionais, que têm por destinatários imediatos todos os membros da federação (União, Estados, Distrito Federal e Municípios). Ademais, o texto legal traz normas federais aplicáveis, exclusivamente, em conflitos em que um dos polos da relação jurídica seja União. Trata-se de competência concorrente e os Estados, Distrito Federal e Municípios deverão apresentar projeto de lei às respectivas casas legislativas para garantir a validade do documento que resulta da autocomposição.

A lei já indicou o órgão que tem competência para promover a aproximação dos interesses em conflito: a Advocacia Pública. Portanto, o mediador não poderá ser escolhido 
pelas partes. Ao cumprir a atribuição de mediador, o agente público da Advocacia Pública deve ser imparcial. Ainda assim, deverá defender o interesse público primário e não o interesse secundário. Como mediador, deverá ainda atuar como facilitador e comunicador entre as partes, ajudando a clarificar questões, identificar intenções e gerar opções de acordos. Deve trabalhar necessariamente para evitar conflitos entre as partes (CALMON, 2015, p. $115)$.

Quanto à mediação poder ser oral e informal, diante dos interesses públicos, deverá haver um mínimo de formalidade, nos termos regulamentares, no sentido de documentar os atos que ocorrerem no processo administrativo. Este é uma exigência para poder promover os controles interno e externo dos acordos que resultarem da autocomposição.

Sobre a autonomia de vontade, não é possível defender-se que tenha a mesma interpretação de quando se está diante da mediação privada. O gestor público tem limites explícitos e implícitos a serem considerados, pois trabalha diante do interesse público. Neste sentido, é fundamental a motivação pela escolha da autocomposição, dos atos praticados e do acordo resultante.

A busca de pacificação pelo consenso está implícita, também, na mediação autorizada para administração pública. Entre os objetivos da mediação, neste âmbito, é trazer melhores e mais rápidas soluções de conflitos que realizam o valor constitucional da eficiência. Quanto ao dever de confidencialidade do mediador em relação a terceiros, não poderá ter o mesmo caráter que tem para mediações de interesses privados. É preciso considerar o dever de publicidade dos atos públicos e o direito à informação à que se refere a Lei n. 12.527/11. Na hipótese desta confidencialidade ser essencial para a resolução do conflito, será possível recorrer às normas de restrição de acesso às informações e classificar o acordo nas categorias de informações sigilosas conforme previsto nos artigos 24 a 29 nos termos permitidos pela lei de acesso à informação.

Os deveres de agir com boa-fé, retidão, honestidade, lealdade e transparência estão entre aqueles que são estruturais para a administração pública, em todo e qualquer momento de suas atribuições. As partes envolvidas na mediação devem ser esclarecidas sobre todos os aspectos que envolvem o conflito, pois permitem conferir a relação de pertinência entre motivo, motivação e finalidade do acordo.

\section{CONCLUSÃO}


A reforma administrativa, conforme Luiz Carlos Bresser Pereira, foi a mudança da atuação do Estado em vistas da promoção da eficiência e qualidade da atuação pública. Tal transformação propunha a mudança da administração burocrática para a gerencial, que compreende a atuação administrativa orientada para maior descentralização, flexibilização e incentivo à inovação. A administração pública gerencial se fixou no alcance de resultados e em virtude disso teve como pressuposto, especialmente, o controle dos atos administrativos a posteriori.

Com o advento da administração pública gerencial marcada, especialmente, pela Emenda Constitucional 19/98, o regime jurídico administrativo continua ser o norteador da função administrativa, mas ganha nova roupagem. Pode-se defender que os valores e regras de estrutura que o compõem serão ainda mais prestigiados. Ou seja, com relação à atuação do gestor que passa a ter mais competências discricionárias, portanto, mais liberdade, é exigida a fundamentação e motivação das suas decisões. Neste contexto, há clara importância dos controles internos e externos tradicionais, acrescidos de oportunidades para o controle social.

O valor da eficiência autoriza a busca por mais caminhos para a gestão dos negócios públicos, além daqueles já previstos em leis. Atualmente há autorização para recorrer às vias da heterocomposição, como a arbitragem (Lei n. 9.307/96 e Lei n. 13.129/15), e as da autocomposição administrativa (Lei 13.140/15). Em ambas, o conflito somente poderá versar sobre direito patrimonial disponível. Este será identificado em face de negócios públicos quando a atuação administrativa puder se dar sem o uso de prerrogativas de autoridade, versar sobre direitos transacionáveis, renunciáveis e alienáveis. Em relação à autocomposição, tal qual a heterocomposição, são facultativas e devem necessariamente partir de uma opção motivada da administração.

A arbitragem no âmbito público, que poderá ser em face de negócios públicos internos e internacionais, se difere em alguns aspectos daquela realizada no âmbito privado. Destaque-se a não vinculação da administração pública ao compromisso arbitral. Mesmo que o patrimônio seja disponível, as cláusulas pactuadas para resolução do conflito podem passar pelo crivo dos controles internos e externos. Se se tratar de arbitragem internacional, o dever de usar o idioma português e a publicação da sentença em território brasileiro.

A autocomposição tem como espécie a mediação. No âmbito privado as partes escolhem o mediador de confiança. No âmbito público, nos termos da lei, tal atribuição deve ser dos membros da Advocacia Pública para resolver conflitos entre órgãos (instituições) da administração e entre particulares. Diferente do regime privado, diante de negócios públicos, 
exige-se um mínimo de formalidade documental e a publicidade dos atos. Em face do princípio da transparência e do regime da mediação privada de confidencialidade, defende-se que seria possível recorrer à proteção e o controle de informações sigilosas nos termos da Lei 12.527/11, que regulamenta o direito de acesso a informação.

Os meios de resolução extrajudicial de conflitos aplicados à seara pública colaboram para a implementação da administração pública gerencial. Isso porque se fundamentam na celeridade, eficiência, alcance de resultados e busca da paz social. Com as suas utilizações é possível visualizar a aproximação entre o interesse privado e o interesse público, pois ambos convergem para concretizar a atuação eficiente da gestão pública.

\section{REFERÊNCIAS}

ARAÚJO, Edmir Netto. Do negócio jurídico administrativo. São Paulo: Revista dos Tribunais, 1992.

BANDEIRA DE MELLO, Celso Antônio. Curso de Direito Administrativo. 28. ed. São Paulo: Malheiros, 2011.

BANDEIRA DE MELlO, Celso Antônio. Curso de direito administrativo. 31 ed. São Paulo: Malheiros, 2014.

BARROCAS, Manoel Pereira. A ordem pública na arbitragem. Revista de Direito Empresarial. São Paulo: Revista dos Tribunais, vol. 5/2014, Set-Out/2014, p. 309-389.

BRESSER PEREIRA, Luiz Carlos. Construindo o Estado republicano: democracia e reforma da gestão pública. Rio de Janeiro: FGV, 2009.

BRESSER PEREIRA, Luiz Carlos; SINK, Peter. (Orgs.). Reforma do Estado e Administração Pública Gerencial. 7. ed. Rio de Janeiro: FGV, 2005.

BRESSER PEREIRA, Luiz Carlos. Reforma do Estado para a cidadania. 34. ed. Brasília: ENAP, 1998.

CALMON, Petronio. Fundamentos da Mediação e da conciliação. 3. ed. Brasília: Gazeta Jurídica, 2015.

DI PIETRO, Maria Sylvia Zanella. Direito administrativo. 29. ed. Rio de Janeiro: Forense, 2016.

FALCÃO, Joaquim; GUERRA, Sérgio; ALMEIDA, Rafael. Soluções alternativas de controvérsias no setor público. Rio de Janeiro: FGV, 2015. 
FIGUEIREDO, Lúcia Valle. Curso de direito administrativo. 8 ed. São Paulo: Malheiros, 2006.

GRAU, Eros Roberto. Arbitragem e contrato administrativo. Revista trimestral de Direito Público. São Paulo, n. 32, p. 14-19, 2000.

MAROLLA, Eugenia Cristina Cleto. A arbitragem e os contratos da administração pública. Rio de Janeiro: Lumen Juris, 2016. p. 69.

MEIRELLES, Hely Lopes. Direito Administrativo brasileiro. 37 ed. São Paulo: Malheiros, 2011.

MUNIZ, Joaquim de Paiva. Os limites da arbitragem nos contratos de concessão de exploração e produção de petróleo e gás natural. Revista de Arbitragem e Mediação, São Paulo, v. 1, n. 2, p. 90-101, maio/ago. 2004.

SALLES, Carlos Alberto de. Arbitragem em contratos administrativos. Rio de Janeiro: Forense, 2011. 